\title{
POLIMORFISMO DO SISTEMA HLA EM UMA AMOSTRA DE MESTIÇOS DA POPULAÇÃO DE TERESINA, PIAUÍ
}

\author{
Semiramis Jamil Hadad do Monte* (Grupo Hla-UfPI), José Machado Moita Neto, Gisele \\ Fabianne Rampim, Natalia Shulzhenko, Andrey Morgun, Maria Gerbase-Delima \\ Trabalho realizado no Laboratório de Imunogenética/UFPI-Universidade Federal do Piauí, \\ Teresina, Pl, e Setor de Imunogenética, Departamento de Pediatria, da UNIFESP - \\ Universidade Federal do Estado de São Paulo - Escola Paulista de Medicina, São Paulo, SP
}

RESUMO - OBjETIVO. Estabelecer as freqüências das especificidades HLA-A, B, DRBI e DQBI numa amostra de mestiços da cidade de Teresina, Piauí, para caracterizar a sua composição genética.

Métodos. A reação em cadeia da polimerase de seqüência de "primers" específicos (PCR-SSP) foi utilizada para determinar as especificidades HLA-A, B, DRBI e DQBI de 97 indivíduos mestiços, saudáveis e não relacionados da cidade de Teresina. A freqüência genotípica foi estimada e comparada com aquelas descritas em amostras de brasileiros caucasianos, portugueses, negros e índios utilizando a Análise de Componente Principal (PCA) e a Análise de Agrupamento Hierárquico (HCA).

Resultados. A freqüência das especificidades HLA-A, B, DRBI e
DQBI observada na amostra de Teresina foi intermediária entre os caucasianos e negros e não foi observada freqüência elevada das especificidades típicas de populações ameríndias. A PCA e HCA demonstraram que os mestiços de Teresina estão muito próximos aos caucasianos e negros e não apresentam similaridades com os índios.

Conclusão. A composição genética do mestiço de Teresina é predominantemente bi-híbrida de genes de origem caucasiana e negra com pouca participação de genes indígenos.

Unitermos: HLA. Polimorfismo. Genética de populações. Grupos étnicos.

\section{INTRODUÇÃO}

O complexo principal de histocompatibilidade, denominado HLA em humanos, compreende um grupo de genes localizados no braço curto do cromossomo 6 e agrupados em três sub-regiões: HLA classe I ( $A, B$ e $C$ ), HLA classe II (DR, DQ e DP) e HLA classe III, sendo que apenas os genes HLA classe I e classe II determinam compatibilidade tecidual'. Os genes que codificam as moléculas HLA são extremamente polimórficos e a função biológica das moléculas HLA classe I e || é apresentar peptídeos aos linfócitos T CD8 + e CD4+, respectivamente. Alguns genes HLA conferem susceptibilidade a certas doenças, por exemplo, o gene HLA-B27 em relação à espondilite anquilosante 2 . Além disso, as moléculas HLA representam os principais aloantígenos (antígenos que diferem entre indivíduos da mesma espécie) relacionados à rejeição de enxertos de órgãos sólidos e à reação de enxerto contra hospedeiro em transplante de

\footnotetext{
*Correspondência:

Laboratório de Imunogenética Universidade Federal do Piauí Campus Petrônio Portela - Bloco 16 CEP: 64049-550 - Teresina - PI
}

células tronco hematopoéticas (transplantes de medula óssea, células tronco do sangue periférico, células de cordão umbilical) $)^{3}$. A identificação dos antígenos HLA (tipificação $H L A$ ) do receptor e de seus potenciais doadores permite a seleção do par receptor/doador com maior grau de compatibilidade HLA e, portanto, com maior chance de sucesso do transplante.

O sistema HLA é altamente informativo em estudos de genética de populações, devido ao seu elevado polimorfismo e ao forte desequilíbrio de ligação entre alelos de locos próximos $^{4}$. Essas propriedades permitem que a tipificação HLA seja utilizada como um instrumento de investigação para caracterizar a composição genética de diferentes povos, uma vez que a freqüência dos alelos HLA e o padrão de haplótipos são característicos de cada etnia e população.

Baseado nisso será feita uma revisão do processo de colonização do Piauí para entender a formação étnica atual da população de Teresina.

A cidade de Teresina está localizada na região nordeste do Brasil com coordenadas geográficas de $05^{\circ} 05^{\prime} 21^{\prime \prime}$ de latitude sul, $42^{\circ}$ $48^{\prime} 07^{\prime \prime}$ de longitude oeste e $72 \mathrm{~m}$ de altitude ${ }^{5}$.
Foi fundada em I 852, como uma capital planejada, e sua população foi constituída a partir de um movimento migratório das cidades do Piauí e de estados vizinhos.

A colonização do Piauí ocorreu em três momentos distintos ${ }^{6,7}$. O primeiro, no século XVII, foi marcado pelo movimento de Entradas e Bandeiras que tinham como finalidade a descrição geográfica da região. Nesta época o Piauí era conhecido como corredor migratório, já que não havia fixação dos colonizadores em solo piauiense. $O$ segundo momento, no século XVIII, caracterizou-se pelo início do povoamento, através da conquista das terras dos índios pelos Bandeirantes e o surgimento das primeiras famílias piauienses. $O$ terceiro momento, ainda nos meados do século XVIII, corresponde à consolidação do povoamento e é marcado por acelerado crescimento demográfico ${ }^{6}$.

A cidade de Teresina, atualmente, tem uma população de 715.360 habitantes $^{8}$, com a seguinte composição étnica: $72 \%$ de mestiços, $23 \%$ de brancos, $4,6 \%$ de negros, $0,01 \%$ de índios, 0,05\% de amarelos ${ }^{9}$. É a principal cidade do Estado e tornou-se um importante pólo de serviços para o meio norte do país, principalmente na área de saúde, especialmente em 
tratamentos médicos de alta complexidade, como o transplante de órgãos e tecidos.

Para o desenvolvimento dos programas de transplante de órgãos e tecidos do Estado, tornou-se importante caracterizar a base genética do tipo étnico dominante da região, já que a seleção do doador para transplante de rim e de células tronco hematopoéticas é baseada em compatibilidade HLA. Assim, o objetivo do presente estudo foi determinar as freqüências das especificidades HLA $A, B$, $D R B \mid$ e DQBI e a participação da etnia branca, negra e ameríndia na constituição do mestiço da cidade de Teresina.

\section{Métodos}

A população estudada consistiu de 97 voluntários mestiços não aparentados, naturais de Teresina e com as duas ascendências parentais do Piauí. As amostras foram obtidas por meio de coleta em múltiplas etapas, com um sorteio inicial de 8 das 12 macro-regiões de Teresina ${ }^{10}$, seguido pelos sorteios dos bairros, ruas e sistematização para a visita da residência a ser incluída.

As amostras de sangue foram coletadas para tipificação HLA classe I e II de apenas um indivíduo de cada residência após obtenção do consentimento informado. Este trabalho foi aprovado pelo Comitê de Ética em Pesquisa da Universidade Federal do Piauí.

\section{Tipificação HLA}

A tipificação HLA foi realizada pela técnica de reação em cadeia de polimerase com primers específicos (PCR-SSP) utilizando kits comerciais (SSP-IL e 2L - One Lambda, Canoga Park, CA, USA). A extração de DNA foi realizada com colunas de captura (Gentra Systems, Minneapolis, MN, USA) e o material isolado foi amplificado em termociclador PTC100 MJ Research, INC (Waterton, MA-USA), utilizando um programa com 30 ciclos. Após uma etapa inicial de desnaturação a $94^{\circ} \mathrm{C}$ por 130 seg, a reação de PCR foi submetida a 29 ciclos a $94^{\circ} \mathrm{C}$ por $10 \mathrm{seg}, 63^{\circ} \mathrm{C}$ por $50-60 \mathrm{seg}$, seguidos pela etapa final de extensão a $72{ }^{\circ} \mathrm{C}$ por 30 seg e, mantido a $4^{\circ} \mathrm{C}$ até ser processada a corrida eletroforética. Os produtos de PCR foram submetidos à eletroforese em gel de agarose a $2 \mathrm{~g} \%$, contendo solução de brometo de etídeo a 0,05 g\%, durante 4 minutos.

O gel foi analisado sob transiluminação ultra-violeta e a foto-documentação foi realizada através do sistema automático Kodak Digital Science - Eletrophoresis Documentation and Analysis System 120, Eastman Kodak Company, NY, USA). A interpretação dos resultados para a determinação da tipificação HLAA, B, DRB। e DQBI de cada doador foi realizada por meio de programa de informática (LMT/DNA HLA Software - One Lambda), seguida de análise manual.

\section{Análise dos dados}

As freqüências fenotípicas (Ff) foram calculadas por meio da divisão do número de vezes que a especificidade aparece na amostra pelo número total de indivíduos estudados. As freqüências genotípicas $(\mathrm{Fg}$ ) foram obtidas pela fórmula: $F g=1-\sqrt{1-F f}$

A distância genética entre a população amostrada de Teresina e os dados obtidos da literatura para as amostras de brasileiros procedentes de São Paulo (São Paulo)"', brasileiros brancos com os ancestrais imigrantes da Europa, principalmente da Itália e Portugal

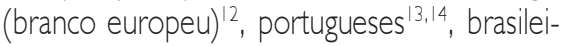
ros negros (negros) ${ }^{15} \mathrm{e}$ índios-terenas ${ }^{16} \mathrm{e}$ guaranis ${ }^{17}$ foram analisados utilizando a $\mathrm{Fg}$ das especificidades HLA, DRBI e DQBI. A análise multivariada desses dados foi feita por meio dos métodos de Análise de Componente Principal $(P C A)^{18}$ e análise de agrupamento hierárquico $(H C A)^{19}$. Todos as cálculos foram realizados com o auxílio do programa - Statistical Package for the Social Science (SPSS, versão 8.0 UFPI). A PCA mostra a posição da população estudada em relação aos dados da literatura, tendo como referencial de construção das novas variáveis (componentes principais - CP) todas as variáveis originais do estudo.

A representação destas componentes em duas dimensões tem grande poder estatístico. $\mathrm{O}$ dendrograma obtido de HCA consiste na construção de diagramas que representam a similaridade entre pares de amostras ou grupos numa escala que vai da identidade até nenhuma similaridade.

\section{Resultados}

As freqüências fenotípicas e genotípicas das especificidades HLA A, B, DRB| e DQB I estão listadas na Tabela I. As quatro especificidades mais freqüentes de cada loco foram: HLA-A, A*02, A*03, A*24 e A*68; HLA-B, B*07, B*44, B*15 e B*35; HLA-DRBI,
$\mathrm{DRB}|*||, \quad \mathrm{DRB}| * 04, \quad \mathrm{DRB}|*| 3$ e $\mathrm{DRB} \mid$ *03 e HLA-DQBI, DQBI*030।, DQB।*06, $\mathrm{DQB} \mid * 02$ e DQB|*05.

Podemos observar na Tabela 2 que as quatro primeiras CPS representam 95\% da variabilidade total das 20 variáveis originais estudadas ( 3 HLA-DRB | e 7 HLA-DQB I).

Dessa forma, estas primeiras componentes contêm as informações estatísticas mais relevantes do estudo, permitindo a redução da dimensionalidade dos pontos representativos das 20 variáveis originais para quatro componentes principais, das quais as duas primeiras (CPI e CP2) representam $74,3 \%$ da variabilidade total do estudo. A CPI, que separou os dados referentes aos grupos indígenas dos demais (Figura I), foi influenciada principalmente pelas variáveis originais $H L A D Q B|* 02, D Q B| * 06$, DRB।*15 e DRB|*03 (peso das variáveis $>0,9$ ). A posição dos grupos indígenas (à esquerda do gráfico) se deve aos elevados valores de Fg para as variáveis HLADRB|*|6, DRB|*08 e DQB|*04 e por conseguinte apresentam-se com pesos altos e negativos na CPI.

A CP2, que explica 19,1\% da variância dos dados, foi influenciada principalmente pela Fg das especificidades HLA-DRB।*04 e DRBI*09. Notadamente a especificidade HLA-DRB।*09 foi a variável determinante do distanciamento genético dos índios das demais populações analisadas, tão bem como entre os Indios guaranis e terenas. Daí, pode ser observado no gráfico da Figura I que o índio terena, conjuntamente com os portugueses, brancos europeus e os mestiços de Teresina estão localizados no quadrante inferior do gráfico decorrente da baixa Fg desta especificidade. Em seguida, a Figura 2 representa de forma visual o esquema de aglomeração (HCA) entre as populações. As duas primeiras populações a se reunirem (estágio I) para constituir um grupo são os brasileiros brancos com ascendência européia e os mestiços de Teresina. No passo seguinte, estágio 2, os brasileiros de São Paulo reúnem-se aos brasileiros brancos com ascendência européia. No terceiro estágio juntam-se os portugueses, seguidos dos negros. As duas populações dos índios formam um agrupamento separado, o que demonstra uma grande distância genética entre eles e as outras populações analisadas. 


\begin{tabular}{|c|c|c|c|c|c|c|c|c|c|c|c|c|c|c|c|}
\hline HLA-A* & $\mathbf{N}$ & $\mathrm{Ff}$ & $\mathrm{Fg}$ & HLA-B* & $\mathbf{N}$ & $\mathrm{Ff}$ & $\mathrm{Fg}$ & $\begin{array}{l}\text { HLA- } \\
\text { DRBI* }\end{array}$ & $\mathbf{N}$ & $\mathrm{Ft}$ & $\mathrm{Fg}$ & $\begin{array}{l}\text { HLA- } \\
\text { DQBI* }\end{array}$ & $\mathbf{N}$ & $\mathrm{Ft}$ & $\mathrm{Fg}$ \\
\hline $\begin{array}{l}01 \\
02 \\
03 \\
11 \\
23 \\
24 \\
25 \\
26 \\
29 \\
30 \\
31 \\
33 \\
34 \\
36 \\
66 \\
68 \\
74\end{array}$ & $\begin{array}{c}10 \\
39 \\
22 \\
9 \\
11 \\
18 \\
2 \\
4 \\
7 \\
11 \\
7 \\
4 \\
4 \\
3 \\
4 \\
15 \\
3\end{array}$ & $\begin{array}{l}0,103 \\
0,402 \\
0,227 \\
0,093 \\
0,113 \\
0,186 \\
0,021 \\
0,041 \\
0,072 \\
0,113 \\
0,072 \\
0,041 \\
0,041 \\
0,031 \\
0,041 \\
0,155 \\
0,031\end{array}$ & $\begin{array}{l}0,053 \\
0,227 \\
0,121 \\
0,048 \\
0,059 \\
0,098 \\
0,011 \\
0,021 \\
0,037 \\
0,059 \\
0,037 \\
0,021 \\
0,021 \\
0,016 \\
0,021 \\
0,081 \\
0,0157\end{array}$ & $\begin{array}{l}07 \\
08 \\
14 \\
15 \\
18 \\
18 \\
27 \\
35 \\
37 \\
38 \\
39 \\
40 \\
40 \\
41 \\
42 \\
44 \\
45 \\
49 \\
49 \\
50 \\
51 \\
52 \\
53 \\
55 \\
57 \\
58\end{array}$ & 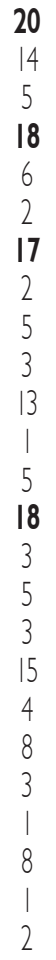 & $\begin{array}{l}0,206 \\
0,144 \\
0,052 \\
0,186 \\
0,062 \\
0,021 \\
0,176 \\
0,021 \\
0,052 \\
0,031 \\
0,134 \\
0,001 \\
0,052 \\
0,186 \\
0,031 \\
0,052 \\
0,031 \\
0,1555 \\
0,041 \\
0,083 \\
0,031 \\
0,001 \\
0,083 \\
0,001 \\
0,021\end{array}$ & $\begin{array}{l}0,109 \\
0,027 \\
0,027 \\
0,098 \\
0,032 \\
0,011 \\
0,093 \\
0,011 \\
0,027 \\
0,016 \\
0,07 \\
0,001 \\
0,027 \\
0,098 \\
0,016 \\
0,027 \\
0,016 \\
0,081 \\
0,021 \\
0,043 \\
0,016 \\
0,001 \\
0,043 \\
0,001 \\
0,011\end{array}$ & $\begin{array}{l}01 \\
03 \\
04 \\
07 \\
08 \\
09 \\
10 \\
11 \\
12 \\
13 \\
14 \\
15 \\
16\end{array}$ & $\begin{array}{c}12 \\
22 \\
26 \\
14 \\
18 \\
1 \\
3 \\
28 \\
3 \\
25 \\
9 \\
16 \\
7\end{array}$ & $\begin{array}{l}0,124 \\
0,227 \\
0,268 \\
0,144 \\
0,186 \\
0,001 \\
0,031 \\
0,289 \\
0,031 \\
0,258 \\
0,093 \\
0,165 \\
0,072\end{array}$ & $\begin{array}{l}0,065 \\
0,121 \\
0,145 \\
0,075 \\
0,098 \\
0,001 \\
0,016 \\
0,16 \\
0,016 \\
0,139 \\
0,048 \\
0,087 \\
0,037\end{array}$ & $\begin{array}{c}02 \\
04 \\
05 \\
06 \\
0301 \\
0302 \\
0303\end{array}$ & $\begin{array}{c}32 \\
16 \\
27 \\
35 \\
36 \\
21 \\
1\end{array}$ & $\begin{array}{l}0,33 \\
0,165 \\
0,278 \\
0,361 \\
0,371 \\
0,217 \\
0,001\end{array}$ & $\begin{array}{l}0,182 \\
0,087 \\
0,151 \\
0,201 \\
0,207 \\
0,116 \\
0,001\end{array}$ \\
\hline
\end{tabular}

\begin{tabular}{lccc}
\hline \multicolumn{4}{c}{ Tabela 2-Importância estatística das primeiras componentes principais (CP) } \\
\hline CP & Autovalor & Variância(\%) & Variância cumulativa \\
\cline { 2 - 4 }$\frac{11,04355}{1}$ & 3,81215 & 55,2 & 55,2 \\
2 & 2,62638 & 19,1 & 74,3 \\
3 & 1,52499 & 13,1 & 87,4 \\
4 & 7,6 & 95,0 \\
\hline
\end{tabular}

$\mathrm{CPI}=$ Componente Principal I, CP2 = Componente Principal 2, CP3 = Componente Principal 3 e CP4 = Componente Principal 4

Ambas as técnicas de análise multivariada utilizadas conjuntamente com as freqüências alélicas obtidas apontam que a população amostrada de Teresina não apresenta traço de similaridade com as populações ameríndias obtidas da literatura.

\section{Discussão}

A população brasileira atual apresenta uma exuberante diversidade genética, resultante da miscigenação entre os três grandes grupos raciais: caucasóides (brancos), negros e ameríndios. Esse processo teve início no século $\mathrm{XVI}$ quando os portugueses aportaram no Brasil. Inicialmente com o ameríndio, seguido de negros e, em meados do século XIX, com brancos de diferentes regiões da Europa, notavelmente Portugal, Itália e Espanha ${ }^{20}$.

No sertão brasileiro, o mestiço tornouse o tipo étnico dominante no século XVIII ${ }^{6}$. Menos de um século depois, Henry Koster ${ }^{6}$ em visita ao Piauí, deixou documentado que o mestiço constituía o tipo étnico dominante da região quando declarou: "(....) a cor dos sertanejos varia do branco, os quais em pouco número, necessariamente ao moreno escuro, com tantas gradações que será impossível encontrar-se dois indivíduos com a mesma variedade de coloração (....)". E esses fatos foram comprovados no censo de 1797, em que foram registrados como mestiços $57,85 \%$ da população cadastrada ${ }^{6}$.

Os dados obtidos no presente estudo consolidam os relatos históricos da colonização do Piauí. Ainda que a região fosse palmilhada por representantes das tribos tupis e tapuias, devido a sua rica bacia hidrográfica, esses foram dizimados quando da chegada dos brancos colonizadores ao Piaú, não permitindo a transferência dos caracteres genéticos de forma significante para os novos habitantes da região. Ao contrário dos índios, os negros sempre foram numericamente expressivos entre os habitantes do Piauí colônia ${ }^{6}$.

Esses fatos podem ser observados no gráfico da Figura I, que representa uma janela estatística privilegiada capaz de demonstrar a proximidade entre as amostras estudadas, em que as populações indígenas analisadas constituem os povos mais distantes dos mestiços de Teresina. Ao contrário, pode ser observado os brancos que formam um íntimo agrupamento com os mestiços de Teresina e de 
Figura I - Análise de componente principal mostrando a relação entre a amostra de mestiços de Teresina (I) e as populaçóes de portugueses (2), brasileiros procedentes de São Paulo (3), brasileiros brancos com os ancestrais imigrantes da Europa (4), brasileiros negros (5) índios terenas (6) e guaranis (7), tendo como base de cálculo as freqüências gênicas das especificidades HLA, DRBI e DQBI. A componente principal I (CPI) extraiu 55,2\% do total da variância e a componente principal 2 (CP2), 19,1\%. Os dados para as populações comparadas foram obtidos de Terasaki and Gjertson, HLA 1997, e outras fontes [ I I- I7]

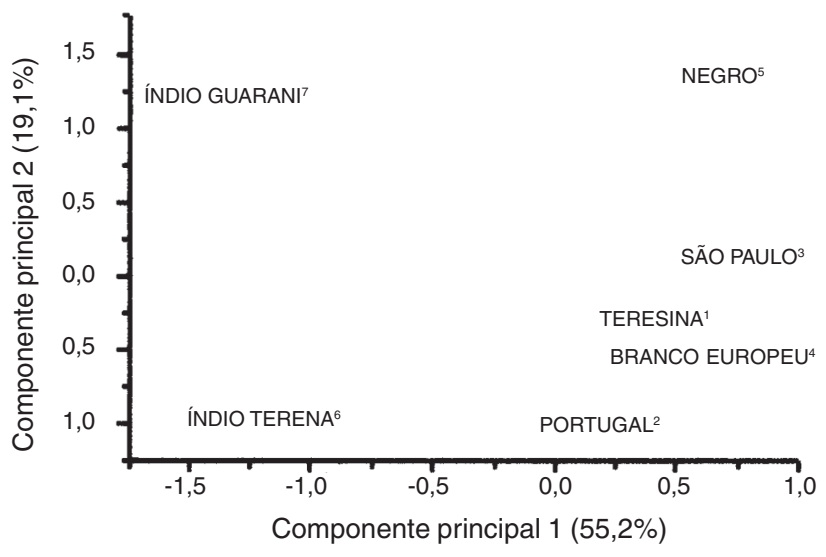

Figura 2-Dendrograma representando o agrupamento dos mestiços de Teresina com as demais populações analisadas da literatura, de brasileiros com ascendência européia, brasileiros de São Paulo, portugueses, brasileiros negros e índios guaranis e terenas por análise de agrupamento hierárquico (HCA). Os dados para as populações comparadas foram obtidos de Terasaki and Gjertson, HLA 1997, e outras fontes [ I I-17]

Dendrogram using Average Linkage (Between Groups)

Rescaled Distance Cluster Combine

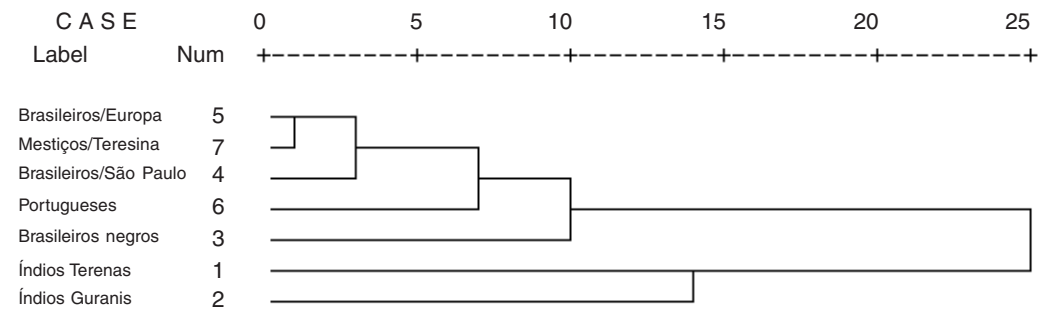

forma intermediária os negros. Daí deduz-se que o mestiço de Teresina tem características genéticas predominantemente de brancos e negros, com pouca participação da etnia ameríndia. $\bigcirc$ mesmo foi observado no dendrograma em que o índio representou o último agrupamento do diagrama sendo, portanto, a etnia mais divergente dos mestiços de Teresina amostrados.

Do ponto de vista histórico da colonização do Brasil, estava previsto que o mestiço constituiria o neo-brasileiro em substituição ao índio, símbolo da nacionalidade que desapareceria como povo nativo. $O$ negro tenderia ao autores $^{22}$, com os estudos de herança cromossomial paterna e materna, comprovaram que a imensa maioria da herança paterna é de origem européia, mais especificamente portuguesa e, em média, 60\% da materna é negra ou ameríndia, retratando o início da história de colonização do Brasil.

Desta forma, o grande poo/ de genes de origem branca no Brasil é originário de portugueses, o que foi comprovado também para essa população de mestiços amostrados, em que o padrão da distribuição dos antígenos HLA- A, B e DRBI foi semelhante ao padrão observado por autores que estudaram as po pulações de Portugal| 13,14,23 e de seus descendentes brasileiros ${ }^{12}$. Ao contrário, a comparação das especificidades HLA dominantes nos mestiços de Teresina estudados diferem significativamente das freqüências observadas em populações ameríndias do Brasil ${ }^{16,17}$, refletindo, em termos biológicos, o fato de que a população atual de mestiços não tem na sua constituição uma forte participação da etnia ameríndia.

Os resultados deste estudo reforçam o conceito do uso dos genes HLA como instrumento de investigação da composição étnica de população e permitem concluir que o mestiço de Teresina apresenta características genéticas predominantemente de origem branca e negra. Estes dados têm implicações para os programas de transplante de órgãos com doador não aparentado do Estado, que têm como determinante da distribuição do órgão a compatibilidade HLA. Uma vez sabendo-se a freqüência dos antígenos HLA do tipo étnico dominante da região, pode-se predizer o tempo em lista de espera do receptor para os programas de transplante de rim e medula óssea com doador não aparentado.

GRUPO HLA-UFPI: Adalberto Socorro da Silva, Aila Maria Veras de Araújo, Antônio Edmilson de Castro, Evaldo Verçosa de Macêdo, Gumercindo Leandro da Silva Filho, Hélida Monteiro de Andrade, Joaquim Xavier de Sousa Júnior, José Adail Fonseca de Castro, Lílian Raquel Mourão de Aguiar, Malba Tânia Miranda Gonçalves Xavier, Régio José Santiago Girão, Ricardo Luz, Robson Férrer Lima Carneiro, Rosana Célia Noleto MagaIhães, Tainá Veras de Sandes Freitas, Victor Eulálio de Sousa Campelo.

Conflito de interesse: não há. 


\section{SUMMARY}

\section{HLA POLYMORPHISM IN A RACIALLY ADMIXED SAMPLE OF THE POPULATION OF Teresina, Piauí}

OBIECTNE. To establish the frequencies of $H L A-A, B, D R B /$ and $D Q B /$ specificities in a racially admixed sample of the city of Teresina, Piaui to characterize its genetic composition.

Methods. Polymerase chain reactionsequence specific primers (PCR-SSP) were used to determine $H L A-A, B, D R B \mid$ and $D Q B I$ specificities of 97 unrelated healthy racially admixed people of Teresina. The genotypic frequencies were estimated and compared to those described in samples of Brazilian Caucasian, Portuguese, Black and Amerindian populations using Principal Component Analysis (PCA) and Hierarchical Cluster Analysis (HCA).

RESULTS. The frequencies of HLA-A,B, $D R B /$ and $D Q B /$ specificities observed in the study sample were intermediate between Blacks and Caucasians and the typical elevation of HLA-specificities seen in the Amerindian race was not observed in the study population. The PCA and HCA analysis revealed that Teresina's racially admixed are very close to both Black and Caucasian and do not show similarities with the Amerindians. CONCLUSION: The genetic composition of Teresina's racially admixed is predominantly bi-hybrid of genes originated from Blacks and Caucasians with little contribution from Amerindian genes. [Rev Assoc Med Bras 2004; 50(4): 422-6]

Key words: HLA. Polymorphism. Population genetics. Ethnic groups.

\section{REFERÊNCIAS}

I. Margulies DH. The major histocompatibility complex. In: Paul WE. Fundamental immunology. 4th ed. Philadelphia: LippincottRaven; 1999. p.263-85.

2. Klein J, Sato A. The HLA system. N Engl J Med 2000; 343:782-6.

3. Erlich HA, Opelz G, Hansen J. HLA DNA Typing and transplantation. Immunity 200I; 14:347-56.

4. Bodner J. HLA and anthropology. In: Terasaki P, Gjertson DW. HLA 1997. Los Angeles: UCLA Tissue Typing Laboratory, 1997. p 45-59.

5. Fundação IBGE. Cidades e vilas do Piauí. Teresina. Rio de Janeiro; 1996.

6. A elite piauiense: família e poder. Teresina: Fundação Cultural Monsenhor Chaves; 1995.

7. Nunes $O$. Estudos de história do Piauí. Teresina: Fundação Cultural Monsenhor Chaves; 1983

8. Fundação IBGE. Censo demográfico 2000: primeiros resultados da amostra. Teresina [CD-Rom]. Teresina; 2002.

9. Fundação IBGE. Censo demográfico 199|. Teresina [CD-Rom]. Rio de Janeiro; 1993.

10. Cartograma [mapa municipal - lista telefônica]. Teresina; TeleListas Ltda; 1999.

I I. Goldberg AC, Marin MLC, Chiarelli ], Rosellis C, KalilJ. Brazil normal. In: Terasaki P, Gjertson DW. HLA 1997. Los Angeles: UCLA Tissue Typing Laboratory; 1997.

12. Moraes ME, Moraes JR. Caucasian brazilian normal. In: Terasaki P, Gjertson DW. HLA 1997. Los Angeles: UCLA Tissue Typing Laboratory; 1997. p.33I.

13. Imanishi T, Akaza T, Kimura A, Tokunaga K, Gjobori T. In: Terasaki P, Gjertson DW. HLA 1992. Los Angeles: UCLA Tissue Typing Laboratory; 1992. p. 1081.

14. Arnaiz-Villena A, Martinez-Lobo J, GómezCasado E, Diaz-Campos N, Santos P, Martinho A, et al. Relatedness among Basques, Portuguese, Spaniards and Algerians studied by HLA allelic frequencies and haplotypes. Immunogenetics 1997; 47:37-43.
15. Moraes ME, Moraes JR. Black brazilian normal. In: Terasaki P, Gjertson, DW. HLA 1997. Los Angeles: UCLA Tissue Typing Laboratory; 1997. p.3।4.

16. Moraes ME, Moraes JR. Terena indians brazilian normal. In: Terasaki P, Gjertson DW. HLA 1997. Los Angeles: UCLA Tissue Typing Laboratory; 1997. p.290.

17. Petzl-Erler. Guarani amerindian Brazil normal. In: Terasaki P, Gjertson DW. HLA 1997. Los Angeles: UCLA Tissue Typing Laboratory; 1997. p.291.

18. World S, Albano C, Dunn III WJ, Edlund K, Esbensen K, Geladi P, Hellberg S, et al. Multivariate data analysis in chemistry. In: Kawalski BR. Chemometrics mathematics and statistics in chemistry. Dordrecht: D Reidel Publishing Company; 1983. p. 17-96.

19. Kaufman L, Mossart DL. Cluster analysis. In: Kawalski BR. Chemometrics mathematics and statistics in chemistry. Dordrecht: D Reidel Publishing Company; 1983. p 393-402.

20. Pena, SD. Homo brasilis: aspectos genéticos, lingüísticos, históricos e socioantropológicos da formação do povo brasileiro. Ribeirão Preto: FUNPEC-RP; 2002.

21. Chor MM, Santos RV. Raça, ciência e sociedade. Rio de Janeiro: Fiocruz; 1996.

22. Pena SD. Retrato molecular do Brasil, versão $200 \mathrm{I}$. In: Homo brasilis: aspectos genéticos, lingüísticos, históricos e socioantropológicos da formação do povo brasileiro. Ribeirão Preto: FUDEC-RP; 2002. p. II-28.

23. Spínola $H$, Brehn A, Willians $F$, Jesus J, Middleton D. Distribution of HLA alleles in Portugal and Cabo Verde. Relationships with the slave trade route. Ann Hum Genet 2002; 66:285-96.

Artigo recebido: 12/08/03 Aceito para publicação: 04//2/03 